\title{
Study of historic nuclear reactor discharge data
}

\author{
D. Copplestone ${ }^{1}$, A. Sutherland ${ }^{1}$, A. McGoff ${ }^{1}$, D. Bennett ${ }^{1}$, A. Matadeen ${ }^{2}$, \\ F. Mok ${ }^{2}$ and A. Bird ${ }^{2}$ \\ ${ }^{1}$ Environment Agency, Warrington WA4 1HG, UK \\ ${ }^{2}$ RM Consultants Ltd, Hitching Court, Abingdon Business Park, Abingdon, \\ Oxfordshire OX14 1RA, UK
}

\begin{abstract}
The UK Government has said that energy companies can invest in new nuclear power stations. As part of this, the safety, security and environmental regulators (the Nuclear Directorate of the Health and Safety Executive and the Environment Agency in England and Wales) are engaged in a process known as generic design assessment (GDA) that was proposed by UK Government to improve the process of consulting on and approving new nuclear power stations. The GDA process is expected to take about $31 / 2$ years to complete. From an environmental perspective, the Environment Agency is interested in assessing whether the proposed reactor designs represent the 'best available techniques' (BAT) with regard to environmental discharges. This paper describes a project that has been assessing BAT for radioactive discharges for analogues (i.e. the previous generation) of four reactor designs on which assessment work started in 2007. Where possible data on environmental discharges has been collated for individual radionuclides for a number of reactor analogues and the discharge performance has been normalized with respect to thermal and electrical outputs to allow trends in the data to be determined. Where possible, explanations for any trends have been identified.
\end{abstract}

\section{INTRODUCTION}

The UK Government has now stated that private sector energy companies should have the option of investing in new nuclear power stations. In 2007, the Environment Agency and the Nuclear Directorate of the Health and Safety Executive started assessing four ${ }^{1}$ generic designs of new nuclear power stations from four reactor vendors [1]. Generic design assessment (GDA) is one of a number of facilitative actions proposed by Government in its May 2007 Consultation Document to improve the process of consulting on and approving new nuclear power stations. It is expected that the robust and detailed assessments will take about $3 \frac{1}{2} 2$ years to complete.

The Environment Agency is particularly interested, from an environmental perspective, in assessing whether proposals for new reactor designs represent the 'best available techniques' (BAT). To achieve this, there was a need to assemble historic discharge data for operating reactors from which the four new designs have evolved or from experiences of operating the new designs and to draw technical links between discharge performance and plant specification, abatement technologies, operation and maintenance.

At the moment four reactor designs have met the Government's criteria laid down in the consultation document "The Future of Nuclear Power: The Role of Nuclear Power in a Low Carbon UK Economy" [2]. Table 1 lists the four reactor designs and these are considered in this paper.

These new designs all aim to improve safety, efficiency and reliability. They all use water technology for neutron moderation and heat removal. The first three designs use light water reactor (LWR) technology whereby light water acts as the moderator and as the method for heat removal from the

1 AECL, the vendor for one of the designs (which uses heavy water as the moderator) withdrew from the GDA process in March 2008.

Article published by EDP Sciences and available at http://www.radioprotection.org or http://dx.doi.org/10.1051/radiopro/20095156 
core. The fourth design uses heavy water as the moderator and light water for heat removal. Of the three LWR designs, two (the AP1000 and the EPR) are pressurised water reactors (PWRs) and one (the ESBWR) is a boiling water reactor (BWR). Within the project, the following information has been sought: a) The gaseous and liquid discharge data for at least six (see Table 1) of the existing operational reactor power stations for each of the proposed new designs. Where possible, this information has been collated for an operational period of 10 years. This discharge data has then been normalised to electrical and/or thermal output. b) Differences between individual reactor performances in terms of their design, operation and maintenance against environmental impact for example, how the discharges are affected by operational matters such as refuelling and maintenance. c) Solid waste arisings for the reactor over the 10 year operational period.

The operational period of 10 years was chosen as it provides sufficient data to identify characteristics and trends in discharges relevant to operational practices and thus allowed the analysis of any trends and step changes in discharge performance to identify key parameters that influence the level of discharges and may help identify what is good practice operationally. Additionally, to evaluate whether better performance on gaseous or liquid discharges may be achieved at the expense of increased quantities (volume and/or activity) of solid wastes, worker dose or non-radiological impact on the environment were collated where the data exists.

Table 1. List of new reactor designs and their analogues used for data gathering.

\begin{tabular}{|l|l|l|}
\hline Reactor Class & Type & Power Station \\
\hline \multirow{3}{*}{ EDF/Areva EPR } & EDF (N4) & Chooz \& Civaux, France \\
\cline { 2 - 3 } & EDF & Golfech \& Penly, France \\
\cline { 2 - 3 } & Konvoi & Neckarwestheim-2, Emsland \& Isar-2 \\
\hline \multirow{3}{*}{ Westinghouse AP1000 } & Westinghouse & $\begin{array}{l}\text { Beaver Valley-2, Byron-2, Comanche Peak-1 \& } \\
\text { Seabrook-1, USA }\end{array}$ \\
\cline { 2 - 3 } & Westinghouse & Sizewell B, UK \\
\cline { 2 - 3 } & Westinghouse & Takahama, Japan \\
\hline \multirow{3}{*}{ GE-Hitachi ESBWR } & BWR, ABWR & Kashiwazaki, Hamaoka \& Shika, Japan \\
\cline { 2 - 3 } & BWR & Shimane, Japan \\
\cline { 2 - 3 } & BWR & Clinton-1 \& Nine Mile Point-2, USA \\
\hline AECL ACR1000 & Candu & $\begin{array}{l}\text { Bruce, Darlington, Gentilly-2, Point Lepreau, } \\
\text { Cernavoda, Wolsong \& Pickering, Canada }\end{array}$ \\
\hline
\end{tabular}

\section{METHODS}

Table 1 lists the reactors considered to be analogues for the four proposed new reactor designs. A reactor was accepted as an analogue if it had a design which is an immediate predecessor to the new design and, ideally, if it had been operational for a period of 10 years or more. For example the two EDF (N4) reactor power stations at Chooz and Civaux are immediate predecessors to the EDF/Areva EPR but have only been operational for eight years. Therefore, the two EDF reactors at Golfech and Penly, predecessor designs to the EDF (N4), were added to the list because they have been operational for more than 10 years.

Having identified the reactor types, information was sought via direct contact with the vendors and operators along with the relevant regulatory bodies (e.g. [3]). In addition other sources, often available online, have been used along with international compilations of data from the IAEA (e.g. [4]), [5-9]. The discharge data for each reactor was extracted from these sources and, where possible, independently verified from different sources (e.g. IAEA data were used to verify data from NEA and vice versa).

The liquid and airborne discharge data was normalised by net electrical output power achieved each year to arrive at the discharge rate per GWeh for each year and for each of the analogue power stations 
a) Comanche Peak Non-normalised

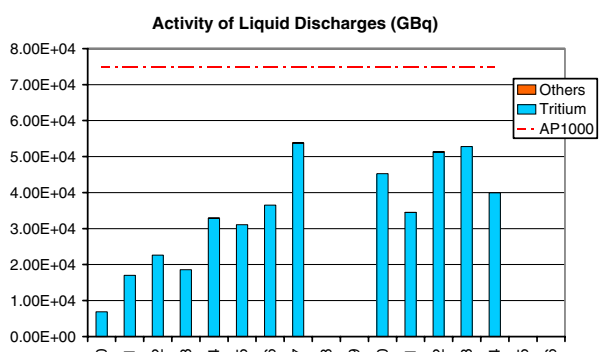

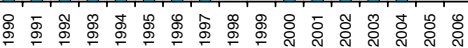

b) Comanche Peak Normalised by Electricity Output

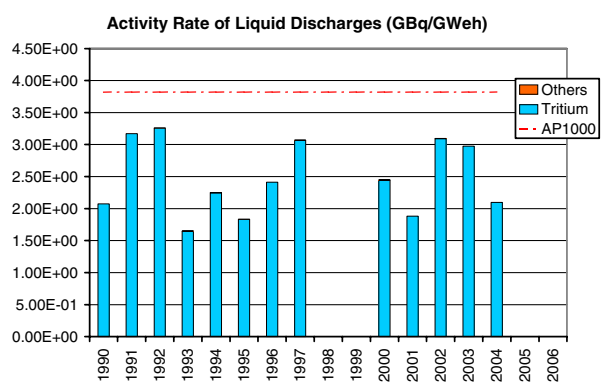

Figure 1. a) Total activity of liquid discharges from Comanche Peak in GBq/a. b) Activity rates for liquid discharges from Comanche Peak GBq per GWeh.

included in this study. For those power stations where multiple reactor cores are in operation, the annual electrical output and online time was obtained by summing the figures for all reactor units.

No information was available for historic annual thermal outputs of the reactors so the thermal outputs were derived from the electrical outputs by multiplying the net electrical output by a factor resultant from the thermal capacity of the reactor divided by the net electrical capacity of the reactor. Both the thermal and net electrical capacities were obtained from the World Nuclear Association (WNA) reactors database [10].

\section{RESULTS}

Once all the data had been checked, the data was summarised, first by each reactor and then by each reactor class, to show the main trends observed in discharges. Importantly, the data was also used to identify points of interest (e.g. high discharge peaks or where data were missing) for each reactor.

Figure $1 \mathrm{a}$ and $1 \mathrm{~b}$ show the non-normalised and normalised data for liquid discharges from the reactors at the Comanche Peak power station, an AP1000 predecessor. During the period from 1990 to 1997 , the non-normalised radioactive discharges appear to increase over time (Figure 1a). Upon normalisation (Figure 1b), the radioactive discharge rates (radioactive discharge per unit of electrical power output) over the same period indicate that there is more of a proportional relationship between the radioactive discharge rate and reactor power output. However, the discharges do not appear to be consistent relative to the power output. For example, the discharge during 1993 was approximately $1.50 \mathrm{GBq} / \mathrm{GWeh}$, whilst during 1991, 1992 and 1997 it was almost twice that figure at greater than $3.00 \mathrm{GBq} / \mathrm{GWeh}$. It is concluded that there is no linear relationship between discharge and power output.

Figure 2a shows the airborne discharges from Pickering A, an ACR-1000 predecessor, which was shut down during the period 1997 to 2003. Despite zero net electrical power output during this period, the level of radioactive discharge was comparable to other years. This does not support the hypothesis that there is a correlation between electrical power generated and radioactive discharge.

Figure $2 \mathrm{~b}$ shows the discharges from Beaver Valley, an AP1000 predecessor. The peak observed in 1996 is believed to have been a result of an abnormal event due to the significantly higher discharge in comparison to the consistent levels for other years and documentation indicating that an abnormal even occurred in 1996: Mis-application of leak sealant (NRC Document EA-96-462).

The mean and the standard deviation were calculated from the normalised radioactive discharges (normalised by net electrical output) for each radionuclide group and for each candidate reactor of each class of reactor included in this study. The mean and mean plus standard deviation (the maximum) was then used to approximate the range of radioactive discharges that might be expected during normal operations, evident from the historic data. This is shown in Table 2. 
a) Pickering A Non-normalised

Activity of Airborne Discharges (GBq)

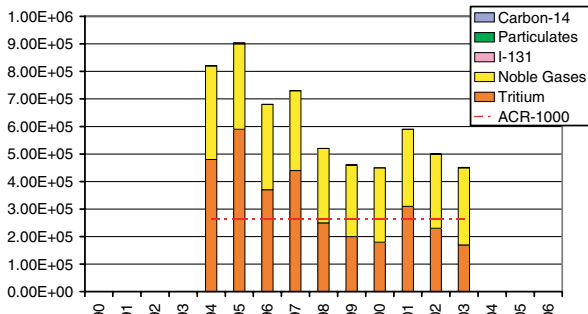

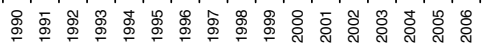

b) Beaver Valley Non-normalised

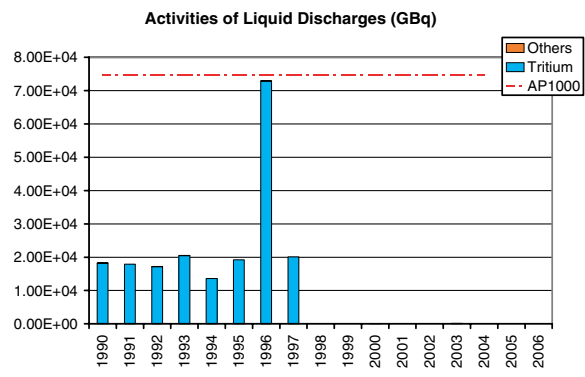

Figure 2. a) Total activity of airborne discharges from Pickering A in GBq/a. b) Total activity of liquid discharges from Beaver Valley in GBq/a.

a) Mean discharge, Candidate Predecessors

Mean Airborne lodine-131 Discharge (GBq)

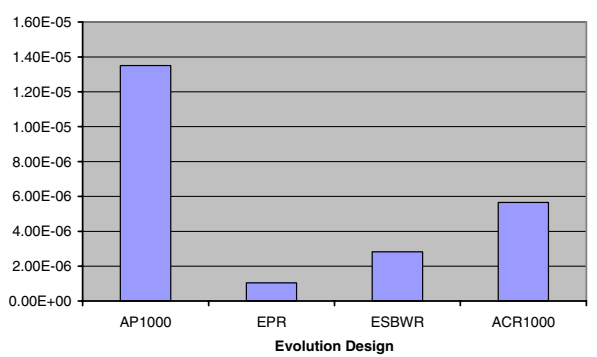

b) Standard Deviation, Candidate Predecessors

Total Air Standard Deviation (GBq)

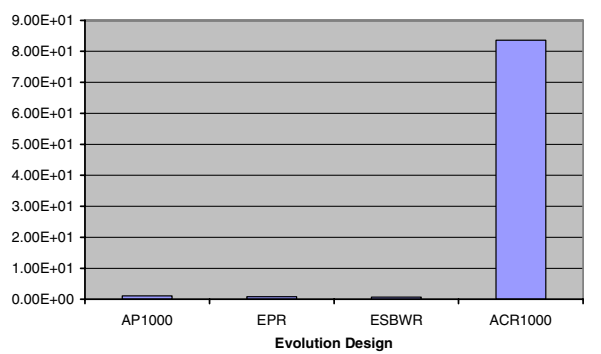

Figure 3. a) Mean airborne iodine- 131 discharge from the candidate predecessors. b) Total airborne standard deviation for candidate predecessors.

Figure 3a indicates that historically and on average the most significant airborne emissions of I-131 have originated from the reactors that are predecessors to the AP-1000 design. Figure $3 \mathrm{~b}$ indicates that historically and on average the most significant fluctuations in radioactive discharges to air have resulted from reactors that are predecessors to the ACR-1000 design. N.B. the mean and standard deviation are calculated from normalised discharge data. However, the results are based on the data available and do not necessarily represent all candidate reactors or all years of study.

A number of significant gaps have been identified. These include lack of information on the solid waste arisings from liquid and gaseous effluent treatment and information on relevant reactor plant abatement techniques that could provide further explanation of the identified trends in the discharge data.

\section{CONCLUSIONS}

The data obtained during this study have been used to identify trends in the discharges of relevant radionuclides from each of the predecessors to the four generic reactor designs considered in this study. The data generally show consistency in the levels of the same radionuclides discharged from the power stations using the same reactor type although there are some notable exceptions and these are listed in the full report [11] with operational factors relevant to individual power stations being important. These include: the number of reactor units present; the electrical and thermal power output by the reactor; and operational factors such as plant shut-down, maintenance and refuelling. 
Table 2. Mean and standard deviation of the data available for the predecessor designs.

\begin{tabular}{|c|c|c|c|c|c|}
\hline Design & Waste stream & $\begin{array}{c}\text { Mean } \\
\text { GBq/GWeh }\end{array}$ & $\begin{array}{l}\text { Standard } \\
\text { GBq/GWeh } \\
\text { deviation }\end{array}$ & $\begin{array}{l}\text { Maximum } \\
\text { GBq/GWeh }\end{array}$ & $\begin{array}{c}\text { Predicted } \\
\text { GBq/GWeh }\end{array}$ \\
\hline \multirow[t]{2}{*}{ AP1000 } & Liquid tritium & $3.03 \mathrm{E}+00$ & $1.58 \mathrm{E}+00$ & $4.61 \mathrm{E}+00$ & $3.82 \mathrm{E}+00$ \\
\hline & Other liquids & $2.18 \mathrm{E}-03$ & $2.44 \mathrm{E}-03$ & $4.62 \mathrm{E}-03$ & $9.69 \mathrm{E}-04$ \\
\hline \multirow[t]{6}{*}{ Total liquid } & & $3.03 E+00$ & $1.58 \mathrm{E}+00$ & $4.61 E+00$ & $3.82 E 00$ \\
\hline & Airborne tritium & $2.12 \mathrm{E}-01$ & $3.26 \mathrm{E}-01$ & $5.38 \mathrm{E}-01$ & $1.32 \mathrm{E}+00$ \\
\hline & Airborne noble gases & $2.80 \mathrm{E}-01$ & 4.16E-01 & $6.96 \mathrm{E}-01$ & $4.17 \mathrm{E}+01$ \\
\hline & Airborne iodine-131 & $1.35 \mathrm{E}-05$ & 4.34E-05 & $5.69 \mathrm{E}-05$ & 4.54E-04 \\
\hline & Airborne particulates & $2.72 \mathrm{E}-06$ & $5.45 \mathrm{E}-06$ & $8.17 \mathrm{E}-06$ & $1.79 \mathrm{E}-04$ \\
\hline & Airborne carbon-14 & $1.80 \mathrm{E}-02$ & $8.60 \mathrm{E}-03$ & $2.66 \mathrm{E}-02$ & $2.76 \mathrm{E}-02$ \\
\hline Total airborne & & $5.10 \mathrm{E}-01$ & $1.11 \mathrm{E}+00$ & $1.62 E+00$ & $4.30 E+01$ \\
\hline \multirow[t]{2}{*}{ EPR } & Liquid tritium & $1.68 \mathrm{E}+00$ & $7.50 \mathrm{E}-01$ & $2.43 \mathrm{E}+00$ & $3.58 \mathrm{E}+00$ \\
\hline & Other liquids & $6.85 \mathrm{E}-05$ & $1.36 \mathrm{E}-04$ & $2.04 \mathrm{E}-04$ & $1.62 \mathrm{E}-03$ \\
\hline \multirow[t]{6}{*}{ Total liquid } & & $1.68 E+00$ & $7.50 \mathrm{E}-01$ & $2.43 E+00$ & $3.58 E+00$ \\
\hline & Airborne tritium & $8.50 \mathrm{E}-02$ & $5.90 \mathrm{E}-02$ & $1.44 \mathrm{E}-01$ & $3.42 \mathrm{E}-02$ \\
\hline & Airborne noble gases & 4.81E-01 & 7.19E-01 & $1.20 \mathrm{E}+00$ & $5.50 \mathrm{E}-02$ \\
\hline & Airborne iodine-131 & $1.05 \mathrm{E}-06$ & $1.95 \mathrm{E}-06$ & $3.00 \mathrm{E}-06$ & $1.57 \mathrm{E}-06$ \\
\hline & Airborne particulates & $1.48 \mathrm{E}-07$ & 2.32E-07 & $3.80 \mathrm{E}-07$ & $2.75 \mathrm{E}-07$ \\
\hline & Airborne carbon-14 & $3.07 \mathrm{E}-02$ & $1.39 \mathrm{E}-02$ & $4.46 \mathrm{E}-02$ & $2.41 \mathrm{E}-02$ \\
\hline Total airborne & & $5.97 E 01$ & 7.93E-01 & $1.39 E+00$ & $1.13 E-01$ \\
\hline \multirow[t]{2}{*}{ ESBWR } & Liquid tritium & $4.04 \mathrm{E}-02$ & $3.25 \mathrm{E}-02$ & $7.29 \mathrm{E}-02$ & $3.79 \mathrm{E}-02$ \\
\hline & Other liquids & $1.37 \mathrm{E}-04$ & $1.88 \mathrm{E}-04$ & $3.25 \mathrm{E}-04$ & 2.65E-04 \\
\hline \multirow[t]{6}{*}{ Total liquid } & & $4.05 E-02^{1}$ & $3.27 \mathrm{E}-02^{1}$ & $7.32 E-02$ & $3.82 E-02$ \\
\hline & Airborne tritium & $6.53 \mathrm{E}-02$ & $8.37 \mathrm{E}-02$ & $1.49 \mathrm{E}-01$ & $2.05 \mathrm{E}-01$ \\
\hline & Airborne noble gases & $3.92 \mathrm{E}-01$ & $6.18 \mathrm{E}-01$ & $1.01 \mathrm{E}+00$ & $1.12 \mathrm{E}+01$ \\
\hline & Airborne iodine-131 & 2.82E-06 & $5.24 \mathrm{E}-06$ & 8.06E-06 & $1.10 \mathrm{E}-03$ \\
\hline & Airborne particulates & $3.42 \mathrm{E}-05$ & $1.52 \mathrm{E}-04$ & $1.86 \mathrm{E}-04$ & $3.59 \mathrm{E}-04$ \\
\hline & Airborne carbon-14 & Not available & Not available & Not available & Not available \\
\hline Total airborne & & $4.57 E-01^{1}$ & $7.03 \mathrm{E}-01^{1}$ & $1.16 E+00$ & $1.14 E+01$ \\
\hline \multirow[t]{2}{*}{ ACR1000 } & Liquid tritium & $3.74 \mathrm{E}+01$ & $3.73 \mathrm{E}+01$ & $7.47 \mathrm{E}+01$ & $1.26 \mathrm{E}+01$ \\
\hline & Other liquids & $2.03 \mathrm{E}-03$ & $2.37 \mathrm{E}-03$ & 4.40E-03 & $1.47 \mathrm{E}-03$ \\
\hline \multirow[t]{6}{*}{ Total liquid } & & $3.74 E+01^{2}$ & $3.73 \mathrm{E}+01^{2}$ & $7.47 E+01$ & $1.26 E+01$ \\
\hline & Airborne tritium & $3.68 \mathrm{E}+01$ & $4.12 \mathrm{E}+01$ & $7.80 \mathrm{E}+01$ & $5.26 \mathrm{E}+00$ \\
\hline & Airborne noble gases & $1.44 \mathrm{E}+01$ & $4.24 \mathrm{E}+01$ & $5.68 \mathrm{E}+01$ & $1.68 \mathrm{E}+00$ \\
\hline & Airborne iodine-131 & $5.66 \mathrm{E}-06$ & $1.10 \mathrm{E}-05$ & $1.67 \mathrm{E}-05$ & 8.42E-07 \\
\hline & Airborne particulates & $1.24 \mathrm{E}-05$ & $5.35 \mathrm{E}-05$ & $6.59 \mathrm{E}-05$ & Not available \\
\hline & Airborne carbon-14 & $1.81 \mathrm{E}-01$ & $2.36 \mathrm{E}-01$ & 4.17E-01 & $2.95 \mathrm{E}-02$ \\
\hline Total airborne & & $5.14 E+01^{2}$ & $8.36 \mathrm{E}+01^{2}$ & $1.35 E+02$ & $6.97 E+00$ \\
\hline
\end{tabular}

One of the main objectives of this study was to identify if there is a clear relationship between radioactive discharges and reactor power output. Following analysis of the available discharge data, it has been concluded that there is no simple, clear or easily explained relationship between radioactive discharges and reactor power output. The following relationships were observed:

1. In some cases, there was evidence to suggest that the relationship between radioactive discharges and reactor power output is proportional. In other cases, there was no relationship between discharge and power output.

2. There were examples where the level of discharge increased as a result of an abnormal event, which was identified in some cases and not in others. Efforts were made to identify abnormal events that may, to some extent, explain any significant peaks in radioactive discharges.

Historically the average discharge of specific radionuclides are markedly different depending on the reactor class of interest. For example, the historical data suggests that the most significant airborne emissions of I-131 have originated from the reactors that are predecessors to the AP-1000 design. 
Comparison between the standard deviations calculated from the historic data for each candidate predecessor indicate that there are some significant differences in the fluctuations in radioactive discharges, depending on the reactor class of interest. For example, the historical data suggests that the most significant fluctuations in levels of airborne radioactive discharges have originated from the reactors that are predecessors to the ACR-1000 design.

These data will be used to inform the Environment Agency's review of the environmental performance of the proposed new nuclear power station designs that might be permitted for use in the United Kingdom in the future.

\section{References}

[1] Health and Safety Executive, New Reactors Website, Background, Assessment Process; 'http://www.hse.gov.uk/newreactors/background.htm' [Accessed January 2008]

[2] Department of Trade and Industry (2007) The Future of Nuclear Power: The Role of Nuclear Power in a Low Carbon UK Economy (Consultation document) The Future of Nuclear Power Future. 207 pp.

[3] Nuclear Regulatory Commission Effluents Database, http://www.reirs.com/effluent/ [Accessed 09 June 2008]

[4] International Atomic Energy Agency database on discharges of radionuclides to the atmosphere and the aquatic environment (DIRATA) - http://dirata.iaea.org/ [Accessed 09 June 2008]

[5] International Atomic Energy Agency; Power Reactor Information System; On-line Database: http://www.iaea.org/programmes/a2/ [Accessed March 2008]

[6] International Nuclear Safety Centre Database. Retrieved from www.insc.anl.gov/ on 14 January 2008.

[7] UNSCEAR Report 2000, Annex C: Exposures to the public from man-made sources of radiation.

[8] European Union; Radioactive Effluents from Nuclear Power Stations and Nuclear Fuel Reprocessing Plants in the European Union (1995-1999 Report and 2000-2003 Report).

[9] OSPAR Commission (2005) The Application of BAT in UK Nuclear Facilities Report; ISBN 1-904426-70-0.

[10] World Nuclear Association. Reactors Database. Available from http://db.world-nuclear.org/ reference/reactorsdb_index.ph [Accessed March 2008]

[11] Study of Historic Nuclear Reactor Discharge Data \& Associated Arising of Solid Radioactive Wastes; RM Consultants Limited; August 2008 